\title{
The Host-Tourist Interaction in a World Heritage Site:
}

\section{The Case of Guimarães}

\author{
José Cadima Ribeiro \\ University of Minho, Braga, Portugal \\ Laurentina Cruz Vareiro \\ Polytechnic Institute of Cávado and Ave, Barcelos, Portugal \\ Paula Cristina Remoaldo \\ University of Minho, Braga, Portugal
}

Guimarães, in the northwest of Portugal, is a city of strong symbolic and cultural significance and its nomination by UNESCO as world heritage, in 2001, enlarged its tourism potential. In this paper we present a few results of a survey that envisaged capturing the Guimarães residents’ perceptions of tourism impacts and their attitudes towards tourists. Specifically, one analyzes the type of relationship that exists between some socio-demographic groups and the perceived tourism impacts, as well as their socio-characteristics and the existing level of interaction between residents and tourists. The survey was implemented between January and March 2010 to a convenience sample of 540 inhabitants of the municipality of Guimarães resulting in 400 questionnaires with complete data. For this, we made use of various statistical techniques. Using a factorial analysis, we can conclude that the three factors used explain $52.3 \%$ of the variance contained in the original variables obtained from the survey. By another side, using a logit model in the analysis and taking as the dependent variable the frequent or very frequent contact with tourists, we found that only the variables referred to perceived positive impacts of tourism, education and the place of residence in urban areas have shown to be statistically significant. We are aware of the multiple ways the issue of residents' perceptions and attitudes towards tourism can be approached and of the difficulties to get useful policy-oriented insights. This paper is a step in that trail.

Keywords: world heritage site, cultural tourism, northwest of Portugal, residents' perceptions, tourism development

\section{Introduction}

The city of Guimarães, in the northwest of Portugal, is a place of strong symbolic and cultural significance. The nomination by UNESCO of its historical centre as world heritage, in December 2001, enlarged its tourism

José Cadima Ribeiro, Full Professor, School of Economics and Management, University of Minho.

Laurentina Cruz Vareiro, Associate Professor, School of Management, Polytechnic Institute of Cávado and Ave.

Paula Cristina Remoaldo, Associate Professor, Department of Geography, Institute of Social Sciences, University of Minho.

Correspondence concerning this article should be addressed to Paula Cristina Remoaldo, Department of Geography, University of Minho, Campus de Azurém, 4800-058 Guimarães, Portugal. E-mail: cris.remoaldo@gmail.com. 
potential. Mostly since that date, as an emergent tourism destination, the city is attracting an increasing amount of visitors.

This paper aims to presenting a few results of a survey that envisaged capturing the Guimarães residents' perception of tourism impacts and their attitudes vis-à-vis the tourists. The survey was implemented between January and March 2010 with a convenience sample of 540 inhabitants of the municipality of Guimarães.

Generally speaking, as expected, results we attained tell us that the Guimarães municipality residents have more propensity to contact with tourists when having a more positive perception of tourism impacts, having a higher education level and live in more urban parishes. The more surprising result was the one telling us that residents with non-tourism related jobs have more propensity to get in contact with tourists than those with tourism related jobs.

In the present paper, we will evaluate some perceptions collected (according to Ap, 1992, as the meaning attributed to an object) and attitudes (according to Ap, 1992, as a person's continuing predisposition or action tendency to some objects). Regarding the issue, lately, Nepal (2008) subscribing Eagly and Chaiken's point of view dated from 1993, considered attitude "as a psychological tendency that is expressed by evaluating a particular entity with some degrees of favour or disfavour” (p. 46).

This paper has to do with a research project that began in October 2009 and will be implemented until the end of 2011. The main objectives of that research project are: (1) to identify the Guimarães residents' perception of the benefits of the tourism industry; (2) to identify the tourists' preferences and their image of Guimarães as a tourism destination; (3) to produce a package of recommendations in terms of local tourism planning and tourism promotion and management which allow the town and its tourism agents to take better profit from tourism development and prevent or minimize tourism negative impacts; and (4) to induce Guimarães authorities and local tourism agents to develop a greater level of partnership with neighbor municipalities in terms of cultural programming and external tourism promotion. In this particular paper, we try to accomplish a few of these goals. The analysis is centered in the first and third aims.

The first section of the paper provides a review of the literature on residents' perception of tourism benefits and their attitudes regarding tourism and tourists. In section 2, we present a few characteristics of the municipality of Guimarães; in section 3 we identify the methodology used, based on the use of a logit model and a factor analysis; and in section 4, we discuss the results we got from the residents' survey. The last section of the paper offers the concluding remarks.

\section{Tourism Impacts and the Host-Tourist Interaction}

The implementation of a sustainable tourism strategy has to take into account the study of the economic, environmental and social impacts of tourists' presence (Brunt \& Courtney, 1999; Williams \& Lawson, 2001; Besculides, Lee, \& McCormick, 2002; Kuvan \& Akan, 2005; Ritchie \& Inkari, 2006). But, if we face tourism as a source of employment creation and of economic growth, we must be aware of the perception and attitudes of host communities and to do its follow up on a frequent basis (Jackson, 2008).

This means that the general planning policy must be aware of the opportunity to reinforce the positive impacts (optimization of the benefits) of the tourism industry and of mitigating or minimize the negative ones felt by host communities (Ritchie \& Inkari, 2006). This approach implies to listen to the host communities regarding 
their concerns about the industry development and to really make residents part of the decision-making process (Brunt \& Courtney, 1999).

The idea that residents must be taken as important stakeholders of the touristic activity, comes from the fact that they are an integrant part of the cultural tourism phenomenon and, being so, can be decisive for the success of tourism destinations (Brunt \& Courtney, 1999; Nepal, 2008; Souza, 2009; Eusébio \& Carneiro, 2010; Cadima Ribeiro \& Remoaldo, 2011). This general idea can be found in papers regarding the issue, produced since the first half of the nineties of the past century, like the ones of Ap (1992) and Lankfort (1994), as underlined by Brunt and Courtney (1999).

The socio-cultural effects of tourism (seen as contributes towards the change in the systems of values, individual behavior, family relationships, collective life styles, safety levels and so forth (Ritchie \& Inkari, 2006)) are better documented in developing countries or, at least, at a more general level than in developed countries, even if the social impacts should be studied in first place (Brunt \& Courtney, 1999). Following Ritchie and Inkari (2006), one might say that is quite questionable that social and cultural impacts of tourism have been approached from a consistent way by research, even if this type of impacts regards people (people impacts), that is the effects on host communities of their direct and indirect association with tourists.

Besculides, Lee, and McCormick (2002) consider socio-cultural benefits (learning, awareness, appreciation, family bonding, community pride, a strong sense of ethnic identity, increased understanding and tolerance) as one of the fourth types of benefits of tourism activity. The other categories are the personal (physical and psychological), the economic and the environmental benefits.

It is well known that, for a long time, most of the investigation undertaken has been concerned with the profile of tourists (their motivations and behaviors) and its impact on the host population. Nevertheless, since the nineties of the twentieth century several studies have investigated the residents' attitudes regarding tourists and tourism development (e.g., Ap \& Crompton, 1993; Lankford \& Howard, 1994; Ryan \& Montgomery, 1994; Hernandez, Cohen, \& Garcia, 1996; Lankford, Williams, \& Knowles-Lankford, 1997). Before these studies, remarkable by the pioneer work made in this field, we should mention Murphy's (1985) research.

In the last twelve years, we can retain the investigations envisaging this same issue held by Lawson, Williams, Young, and Cossens (1998), Besculides, Lee, and McCormick (2002), Kuvan and Akan (2005), Sharma and Dyer (2009), McDwall and Choi (2010), among several others.

Recent literature (e.g., McDwall \& Choi, 2010) tells us that, when residents have a positive perception about the benefits of tourism, they tend to develop more favorable attitudes concerning tourism, and that contributes to a more interaction with visitors. This interaction can be important to achieve an increase of satisfaction of the tourists and to the developing of customer loyalty (Eusébio \& Carneiro, 2010). From this, we can also conclude that "work with people" and not only "work to the people" must be a central concern in any strategy of touristic development (Eusébio \& Carneiro, 2010).

As mentioned, residents can give an important contribution to the identification and measuring of tourism impacts (Getz, 1994; Zhang, Inbakaran, \& Jackson, 2006), this way, allowing the authorities to adjust their policies towards tourism. By another side, the identification and measurement of these impacts allows identifying the quality of life felt by the host community. This is quite relevant as we must consider that not only tourism can be a major contributor to local community prosperity, but also the phenomenon "will shape the lifestyles, societal 
structures, and inevitably the quality of life of the host communities” (Crouch \& Ritchie, 1999, p. 138).

The residents' perception of tourism impacts is a quite recent field of research in Portugal. Until now, just a few empirical studies were produced, namely the ones of Monjardino (2009), Souza (2009), Eusébio and Carneiro (2010), and Vareiro, Cadima Ribeiro, Remoaldo, and Marques (2011).

Taking different approaches, most of the research conducted explores residents' socio-demographic characteristics, trying to establish a link between that and their perceptions and attitudes regarding the tourism industry (e.g., Lawson, Williams, Young, \& Cossens, 1998; Brunt \& Courtney, 1999; Besculides, Lee, \& McCormick, 2002; Kuvan \& Akan, 2005; Sharma \& Dyer, 2009).

There are several factors that can influence residents' attitudes towards tourism and tourists (Mason \& Cheyne, 2000). The major difficulty regarding the issue is that the relationship between those factors and the perceptions of the tourism impacts has largely revealed to be inconsistent from research to research (Pearce, Moscardo, \& Ross, 1996; Lawson, Williams, Young, \& Cossens, 1998). Even so, some empirical research suggest that socio-demographic variables, such as gender, age, birthplace and level of community attachment, ethnicity, education level and length of residence can affect it.

Other variables that can also influence the residents' perceptions are: tourist-resident contact; proximity to resorts; economic dependency; economic and tourism development; level of knowledge about tourism; and involvement of residents in tourism decision making (Cordero, 2008; Sharma \& Dyer, 2009). Some of those variables do not have been taken into account by several of the researchers. Recently, in a critical theoretical and methodological review of the published investigations since the seventies of the 20th century, Cordero (2008) related that to the considerable variety in theoretical and methodological approaches that have been followed. That would tend to difficult the academic progress in the study of host communities' tourism perceptions. From there, also, would result the lack of theoretical foundations of the approaches to the issue that have been taken (Cordero, 2008).

Explicitly, the contradictions in the findings about residents' perceptions and attitudes towards tourism can result from circumstances such as: "the variation of instruments; sampling techniques; methodologies; and theoretical frameworks perceptions” (Cordero, 2008, p. 39). Additionally, according to the before mentioned author (Cordero, 2008, p. 39), most of the findings “cannot be generalized outside of the sampling frame”. Being so, the only thing we can conclude is that the empirical literature indicates mix findings when the relationship between the residents' perceptions and attitudes towards tourism and their socio-demographic features is approached.

There are different types of studies dealing with the host-tourist interaction: the ones that make the analysis of the interaction between visitors; the ones that analyse the interaction between residents' and visitors from the visitors' perspective; and, finally, the ones that make the analysis of the interaction between residents' and visitors from the residents' perspective. The studies conducted by Brunt and Courtney (1999), Besculides, Lee and McCormick (2002), Nepal (2008), Eusébio and Carneiro (2010), as the one conducted with the aim of our research project is part of this last group.

The social contact (as the personal contact between a visitor and a resident) can occur in many situations. In the case of a cultural destination, it can happen when the visitor is: buying some products to the residents; using some services (e.g., hotels, restaurants); visiting a monument or using public transportation (bus, taxi); 
participating in some cultural activities (e.g., concerts, festivals or fairs); asking for some information or exchanging ideas.

Even if there are several opportunities for the host-visitor interaction, this type of contact is generally temporary, brief, superficial, commercial and formal in some occasions, as well as asymmetric from the point of view of the visitor or the one of the residents (De Kadt, 1979; Reisinger \& Turner, 2003, in Eusébio \& Carneiro, 2010). The asymmetric relationship results from the fact that the resident is generally working, trying to satisfy his need of survival, while the visitor is trying to benefit from his/her leisure time, satisfying his/her recreation needs, profiting from moments that can give him/her pleasure (Eusébio \& Carneiro, 2010).

In the case of Guimarães, as the visitors are in the majority of cases from countries endowed with cultural features very similar to the Portuguese one, we must assume that the values systems of tourists and residents should not be very different.

Brunt and Courtney (1999) used the frequency and the type of contact to evaluate the interaction between host and visitor. Some limitations of that methodological approach can pointed out, namely, the ones that result from the impossibility of taking into account the plurality of spaces existing in the destination, and of acknowledging the kind of interaction verified, that surely can be quite different (Eusébio \& Carneiro, 2010).

Taking that in account, in our survey of 25 questions, we made appeal to the frequency of the interaction (question 5) and also to the kind of interaction that occurred, namely, if it took place in the aim of a job (question 6).

As emphasized, we realize that there are few studies dealing with the interaction of host-visitor and that there are even fewer dealing with the factors that command that interaction. This took us of paying a special attention to those research issues with the aim of our empirical research.

Most of the times, residents tend to value the positive economic impacts (the most important impacts recognized) more than the negative economic ones. The more common positive economic impacts identified are: the increase of the rate of growth of the local economy; the increase of investment; the increase of the creation of businesses companies; and the increase of employment. Other kinds of impacts are also revealed, as the social and cultural ones (development of cultural activities; restoration and requalification of historical centers; and the possibility of cultural interchange).

Some investigation deals with the negative impacts-the increase of the traffic; the pressure felt in the demand of some local services, such as security and health; and the change or vanishing of local culture (Eusébio \& Carneiro, 2010).

As mentioned, while residents generally welcome economic opportunities associated to tourism development, they tend to turn anxious when they perceive potential negative impacts of the industry on the community's well-being, like degradation of their surrounding natural environments or competition in the access to some equipments and services (Nepal, 2008).

\section{Methods}

\section{Main Objectives and Some Data About the Territory}

The purpose of this study is to estimate a model that relates the probability of residents having a frequent or very frequent contact with tourists to a set of independent variables measuring residents' perceived impacts of tourism and their socio-demographic characteristics. Consequently, based on the previous literature review, 
the research hypotheses can be summarized as follows:

H1: The perception of positive impacts/benefits of tourism by residents positively influences their probability of having a frequent or very frequent contact with visitors.

H2: The perception of negative impacts/costs of tourism by residents negatively influences their probability of having a frequent or very frequent contact with visitors.

H3: The socio-demographic characteristics of residents influence their probability of having a frequent or very frequent contact with visitors.

H3.1: Age of residents influences the probability of having a frequent or very frequent contact with visitors.

H3.2: Gender of residents influences the probability of having a frequent or very frequent contact with visitors.

H3.3: Level of education of residents influences the probability of having a frequent or very frequent contact with visitors.

H3.4: Income of residents influences the probability of having a frequent or very frequent contact with visitors.

H3.5: Linkage of residents to tourism industry influences the probability of having a frequent or very frequent contact with visitors.

H3.6: Residence in urban areas influences the probability of having a frequent or very frequent contact with visitors.

It is important to mention that Guimarães is located in the Ave Valley, in the northern part of Portugal, and is at present one of the most important towns in that territory, after Oporto, Vila Nova de Gaia and Braga. Guimarães has revealed during last decades a sustainable population increase (162,636 inhabitants in 2008) (Instituto Nacional de Estatística, 2009), showing a rate of young population which places it as one of the youngest municipalities in the northern part of the country. On the other hand, the hosting of the 2012 European Capital of Culture and its certification by UNESCO, in 2001, as World Heritage Site by UNESCO are being facilitating factors of its external visibility in the way to capturing an increasing amount of visitors (Vareiro, Cadima Ribeiro, Remoaldo, \& Marques, 2011). A sustainable growth in the number of visitors is reached since 2000. The before mentioned kind of certification and the fact that Guimarães is called "The cradle of the nation" (place of birth of D. Afonso Henriques, first king of Portugal) have been until present the supports of tourism promotional strategy followed by the local authorities.

\section{Questionnaire Design}

Taking into account the objectives underlined for this study, we made use of a survey applied in a more comprehensive project about the tourism industry in Guimarães. One of the main questions of the questionnaire (question 5) was: In your spare time you see tourists? In relation with that question, the question 11 included a total of 14 items encompassing residents' perceptions of tourism impacts. These items were selected based on previous empirical studies concerning economic, socio-cultural and environmental tourism impacts (Williams \& Lawson, 2001; Besculides, Lee, \& McCormick, 2002; Kuvan \& Akan, 2005; Jackson, 2008; Sharma \& Dyer, 2009). Additionally, we followed and adapted a questionnaire applied by Monjardino (2009) to Azores Islands, dealing with the issue of residents' perception of its tourism development. 
Since Guimarães is a cultural destination, we decide to approach the socio-cultural impacts: six items were used to measure the perceived positive socio-cultural impacts and three items the negative socio-cultural impacts; three items were used to measure economic benefits and one item tried capturing the perceived economic problems; and, finally, one item addressed the perceived negative environmental impacts. Responses to the items were all measured in a five-point Likert scale ( 1 = completely disagree and $5=$ completely agree). Respondents' socio-demographic information (age, gender, education level, household income, occupation, link to the industry) was also included in the questionnaire. A few geographic variables, such as being born in the municipality, the length of time the person had been living in the municipality of Guimarães and the parish where he/she was living were also included.

\section{Data Collection}

Taking into account the objectives underlined, we based the research on primary and secondary data. As primary data, we conducted a survey with the residents on their perceptions of the impacts of tourism. The questionnaire was applied to a convenience sample of 540 residents from the municipality of Guimarães, between January and March 2010.

In order to create the sample, we contacted four public local secondary schools and one public professional school. Three of the schools involved in are situated nearby the historical center, one is located two kilometers away from the city of Guimarães and another is in Caldas das Taipas, which is the second most important urban center of the municipality. This allowed us to almost cover the 69 parishes which, administratively, constitute the municipality.

We chose the high schools as a way to include in our survey, in theory, three generations of inhabitants: the 15-24 years old; the 25-64 years old; and the 65 or more years old residents. With that aim, we established contact with the head of each school and asked for the assistance of teachers who could hand out the questionnaires to their pupils. Following that process, in a second moment, the students who were over 16 years old were asked to include their brothers/sisters, parents and grandparents in the study by asking them to also answer the survey. Each teacher gave three questionnaires to each student over 16 years old and asked them to return them within a two weeks time schedule.

As the sample revealed itself to be biased, under-representing the 25-64 years old section of Guimarães residents, in a second phase, we asked adults that were making use of the services of the municipal council to fill in the same questionnaire. That took place during the month of March.

A pre-test involving 19 Guimarães residents had been conducted between November 30-December 4, 2009. A total of 540 usable surveys were returned, which constituted a response rate of $67.1 \%$ of the questionnaires handed out. Examination of missing data indicated that this occurred completely at random.

The simplest and most direct approach for dealing with missing data is the complete case approach, considering only those questionnaires with complete data (Hair, Anderson, Tatham, \& Black, 1998). After eliminating incomplete answers, 400 with complete data were kept for analysis.

\section{Data Analysis}

Since we have several variables (14) to measure perceived impacts of tourism in Guimarães, one decide making use of factorial analysis (with varimax rotation and using principal components as extraction method) to 
reduce data, transforming the original set of 14 variables into a smaller set of representative factors. Further, we use those factors (that are continuous variables), instead of the original set of 14 variables, as explanatory variables in a logit model, thus simplifying this model. The use of factorial analysis in this study relies on a previous diagnosis based on the computation of the Kaiser-Meyer-Olkin (KMO) statistics and on the Bartlett test. Cronbach's alpha coefficients evaluate the reliability of the obtained factors.

Afterwards, a logit regression model was estimated in order to analyze the effect of each independent quantitative variable (the impacts factors plus the variable of age) together with a set of dummy variables (envisaging to measure the influence of gender, education, income, link to the industry and place of residence) on the probability of residents having a frequent or very frequent contact with tourists. By recoding the statement "In your spare time do you see tourists?" into a binary variable, in which the code 1 identifies residents that kept a frequent or a very frequent contact with tourists and the code 0 the remaining residents, we got the dependent variable.

Therefore, in order to estimate the probability of a resident having a frequent or very frequent contact with tourists, the following logistic probability function was considered:

$$
\log \left(P_{i} / 1-P_{i}\right)=X_{i}{ }^{\prime} \beta
$$

where $\log \left(P_{i} / 1-P_{i}\right)$ is the logarithm of the odds-ratio of the probability of having a frequent or very frequent contact with tourists over the probability of not having a frequent or very frequent contact. The parameter vector $\beta$ measures the change in the odds-ratio of a change in a unit of an explanatory variable.

In order to estimate the effects on the probabilities directly, the marginal effects must then be estimated (Loureiro \& Jervell-Moxnes, 2004; Wooldridge, 2006).

The previously presented statistical model is based on a latent and continuous unobservable variable, which corresponds to the utility that each resident maximizes by having or not having a frequent or very frequent contact with tourists (identified by the variable contact $_{i}{ }^{*}$ ).

This unobserved variable is a function of observed demographic and geographic characteristics of the residents and the perceived impacts (represented by a vector of variables $X_{i}$ ). Thus, the latent model is:

$$
\text { contact }_{i}^{*}=X_{i}^{\prime} \beta+\epsilon_{i}
$$

Since utility is something that cannot be directly observed, we model the observable variable or decision to have a frequent or very frequent contact with tourists, contact ${ }_{i}$, which depends on whether or not the utility gained is greater or smaller than zero. The decision to have a frequent or very frequent contact with tourists is observed if and only if the latent variable is greater than zero. Not having a frequent or very frequent contact is observed when the latent variable is less than or equal to zero (Loureiro \& Jervell-Moxnes, 2004).

The model to be estimated has the following form:

$$
\begin{aligned}
\text { contact }_{i}^{*} & =\beta_{0}+\beta_{1} f a c 1+\beta_{2} f a c 2+\beta_{3} f a c 3+\beta_{4} a g e+\beta_{5} \text { gender }+\beta_{6} \text { education }+\beta_{7} \text { income } \\
& +\beta_{8} \text { linksector }+\beta_{9} \text { urbparish }+\epsilon_{i}
\end{aligned}
$$

The explanatory variables used in the model were: positive impacts $(f a c 1)$, negative impacts $(f a c 2)$, governance (fac3), age, gender, education, income, link to the sector (linksector) and urban place of residence (urbparish).

In order to include them in the logit model, the variables education and income were transformed into dummy ones: education was defined as being 1 if residents possess at least nine years of education and 0 
otherwise; income was defined as being 1 if residents earn more than 1,000 $€$ and 0 otherwise.

Gender, work and urbparish were also taken as dummy variables (gender: 1 = female, 0 = male; linksector: 1 if the respondent works or has worked in tourism activities — has or had a link with the sector —and 0 otherwise; urbparish: 1 if the place of residence is a predominant urban parish and 0 otherwise), and $f a c 1, f a c 2$, fac 3 and age as quantitative variables.

To estimate the logit model as defined in equations (1), (2) and (3), and to obtain descriptive statistics to profile the respondents, the Statistical Package for Social Sciences software (SPSS version 16.0) was used.

The analysis of all results obtained from both (descriptive and analytical) methodological approaches will be detailed presented in the next section.

\section{Results}

\section{Profile of Respondents}

Table 1 summarizes the socio-demographic profile of the survey sample. Over one half of the respondents (53.2\%) were female. This result is close to the one of other studies, such as the one of Sharma and Dyer (2009). The sample was compared with municipality figures to check its representativeness. Regarding the gender characteristics of the municipality of Guimarães, following the 2008 forecasts from the National Institute of Statistics, we found that $50.8 \%$ of its residents were females.

Table 1

Some Respondents' Characteristics

\begin{tabular}{|c|c|c|c|c|c|}
\hline & No. & $\%$ & & No. & $\%$ \\
\hline Gender & & & Work in sector & & \\
\hline Male & 187 & 46.8 & No & 333 & 83.2 \\
\hline Female & 213 & 53.2 & Yes & 67 & 16.8 \\
\hline Age & & & Place of residence & & \\
\hline $15-24$ & 126 & 31.5 & AMU & 81 & 20.2 \\
\hline $25-64$ & 213 & 53.2 & APU & 319 & 79.8 \\
\hline 65 and more & 61 & 15.2 & & & \\
\hline Education & & & Income & & \\
\hline at least 6 years & 102 & 25.5 & Up to $500 €$ & 49 & 12.2 \\
\hline 7th-9th grade & 86 & 21.5 & $501-1,000 €$ & 119 & 29.8 \\
\hline 10th-12th grade & 140 & 35.0 & $1,001-2,500 €$ & 128 & 32.0 \\
\hline University & 72 & 18.0 & More than 2,500 $€$ & 35 & 8.8 \\
\hline
\end{tabular}

Note. Source: Authors’ own survey data.

The largest age cohort of respondents was the one aged between 25-64 years old (53.2\%), followed by the 15-24 years old (31.5\%) and the 65 or more years old (15.2\%) ones. Despite the effort made to insure a better representativeness of Guimarães' population, the cohort of the 25-64 years old respondents remained under-represented in the sample (69.5\% was the corresponding municipality proportion).

A total of $31.7 \%$ of the survey respondents was endowed with a secondary education and $18.0 \%$ with a higher education level. Taking the population universe, the most represented education level in the municipality in 2001 was that having a primary (6 years) education level (55.7\%) and only 6.6\% of Guimarães’ residents had a higher education level. We can, of course, admit some changes in those figures occurred after 2001, but the 
improvement attained in the level of education rates would not be enough to insure the representativeness of the respondents of our sample.

According to the empirical literature review, residents' perceptions of tourism impacts and their attitudes towards tourists are also influenced by several other factors, like the contact they establish with them, their economic dependence from the industry, the place of residence, and the level of income. Since the majority of the parishes in the municipality are not endowed with any tourism attraction, we found not strange that the majority of respondents (60.5\%) lived in a parish with very low or no tourism potential (in order to be classified has a parish with tourism potential, the parish should have, at least, two specific tourism infrastructures). On the other hand, 79.8\% of the survey respondents live in Predominantly Urban Areas (APU).

\section{Factor Analysis}

Before approaching the factorial analysis results, the factorability of the 14 impact statement items was examined. Firstly, applying the Kaiser-Meyer-Olkin measure of sampling adequacy, we got the result 0.806, that is, a figure above the recommended value of 0.6 , and the Bartlett's test of sphericity turns to be significant ( $p<$ 0.000). Finally, the communalities were all above 0.4, except one, further confirming that each item shared some common variance with other items. Given these overall indicators, factorial analysis was conducted with all 14 items.

To examine the dimensions underlying the residents' impact statements, a principal component factor analysis with varimax rotation was undertaken. During several steps, one item was eliminated because it was not correlated at least 0.3 with at least one other item and failed to meet a minimum criteria of having a primary factor loading of 0.4 or above. In those circumstances, it was removed from further analysis and the factors analysis was undertaken again. Thereafter, a principal components factors analysis was conducted again with the remaining items.

The factor loading matrix for this final solution is presented in Table 2. A total of 13 items were loaded on three factors with Eigen values greater than 1 . These factors explained $52.3 \%$ of the variance and were labeled "positive impacts, negative impacts and governance".

Table 2

Factor Analysis Results With Varimax Rotation of Residents'Perceptions of Tourism Impacts in Guimarães

\begin{tabular}{|c|c|c|c|c|c|c|c|c|}
\hline Components & $\begin{array}{l}\text { Factor } \\
\text { loading }^{\text {a }}\end{array}$ & Communalities & $\begin{array}{l}\text { Item } \\
\text { means }\end{array}$ & $\begin{array}{l}\text { Standard } \\
\text { deviation }\end{array}$ & Eigenvalues & $\begin{array}{l}\% \text { of } \\
\text { variance }\end{array}$ & $\begin{array}{l}\text { Cumulative } \\
\%\end{array}$ & $\begin{array}{l}\text { Reliability } \\
\text { alpha }\end{array}$ \\
\hline Factor 1: Positive Impacts & & & 4.09 & & 3.418 & 26.289 & 26.289 & 0.760 \\
\hline $\begin{array}{l}\text { Encourages local culture and } \\
\text { handicrafts }\end{array}$ & 0.750 & 0.531 & 4.25 & 0.716 & & & & \\
\hline Creates jobs for residents & 0.720 & 0.475 & 4.13 & 0.785 & & & & \\
\hline $\begin{array}{l}\text { Helps supply new services for } \\
\text { residents }\end{array}$ & 0.718 & 0.451 & 3.90 & 0.781 & & & & \\
\hline $\begin{array}{l}\text { Promotes contact with different } \\
\text { cultures }\end{array}$ & 0.623 & 0.552 & 4.37 & 0.663 & & & & \\
\hline $\begin{array}{l}\text { Aids the conservation and } \\
\text { restoration of historic buildings }\end{array}$ & 0.614 & 0.462 & 4.19 & 0.782 & & & & \\
\hline $\begin{array}{l}\text { The quality of services (e.g., } \\
\text { restaurants, cafes, bars, shops) in } \\
\text { Guimarães is now better due to } \\
\text { tourism }\end{array}$ & 0.524 & 0.594 & 3.70 & 0.833 & & & & \\
\hline Factor 2: Negative Impacts & & & 2.467 & & 2.112 & 16.247 & 42.537 & 0.735 \\
\hline
\end{tabular}


(Table 2 continued)

\begin{tabular}{|c|c|c|c|c|c|c|c|c|}
\hline Components & $\begin{array}{l}\text { Factor } \\
\text { loading a }\end{array}$ & Communalities & $\begin{array}{l}\text { Item } \\
\text { means }\end{array}$ & $\begin{array}{l}\text { Standard } \\
\text { deviation }\end{array}$ & Eigenvalues & $\begin{array}{l}\% \text { of } \\
\text { variance }\end{array}$ & $\begin{array}{l}\text { Cumulative } \\
\%\end{array}$ & $\begin{array}{l}\text { Reliability } \\
\text { alpha }\end{array}$ \\
\hline $\begin{array}{l}\text { Tourism limits the access of } \\
\text { residents to leisure sites and } \\
\text { equipment }\end{array}$ & 0.770 & 0.581 & 2.39 & 1.030 & & & & \\
\hline $\begin{array}{l}\text { Generates excessive noise in the } \\
\text { Historical Center }\end{array}$ & 0.744 & 0.405 & 2.46 & 1.023 & & & & \\
\hline $\begin{array}{l}\text { Local people change their behavior } \\
\text { in an attempt to mimic the behavior } \\
\text { of tourists }\end{array}$ & 0.739 & 0.597 & 2.42 & 0.975 & & & & \\
\hline Increases crime rates & 0.662 & 0.571 & 2.60 & 0.989 & & & & \\
\hline Factor 3: Governance & & & 3.453 & & 1.275 & 9.809 & 52.345 & 0.544 \\
\hline $\begin{array}{l}\text { Guimarães has control on tourism } \\
\text { management and planning }\end{array}$ & 0.702 & 0.549 & 3.27 & 0.848 & & & & \\
\hline $\begin{array}{l}\text { Money spent by tourists is kept by } \\
\text { municipality agents and residents }\end{array}$ & 0.697 & 0.512 & 3.51 & 0.769 & & & & \\
\hline $\begin{array}{l}\text { Residents have easy access to } \\
\text { services used by tourists }\end{array}$ & 0.688 & 0.524 & 3.58 & 0.831 & & & & \\
\hline
\end{tabular}

Factor 1 is related with the positive economic and social impacts of tourism development in Guimarães, and is responsible for explaining $26.3 \%$ of the total variance found. It is followed by factor 2 ( $16.2 \%$ of total variance), which comprises items related to the negative economic and social impacts, including attributes related to noise, social behavior, crime and residents access to recreational sites. The final factor represents $9.8 \%$ of the statistical variance found and is associated with the governance of the territory and the impacts related to the tourism equipment available and its use.

The internal consistency of the items within each dimension was measured by examining the Cronbach reliability alphas. Nunnally (1978) suggests that reliability alphas close to 0.70 indicates a high level of internal consistency between the individual scale items and the related factors. These show a high level for factors 1 and 2 but lower for factor 3, suggesting lower reliability.

\section{Logit Model}

When analyzing the frequent or very frequent contact with tourists via a logit model (as presented in Table 3 ), we find that variables representing the perceived positive impacts of tourism, the governance of territory, the income and the place of residence in urban areas all present a coefficient with a positive sign. But, in fact, only perceived positive impacts, education and the place of residence in urban areas are statistically significant ( $p$-value $<0.1)$.

As said before, the perception of positive impacts of tourism and the level of education are variables that can help to explain the interaction that residents keep with visitors. In fact, as more positive are the perceptions towards tourism and as more persons endowed with a higher level of education, more receptive to contact with persons of different cultures tend to be, and, also, better informed about the phenomenon of cultural tourism tend to be. A review of the empirical literature evidences cases which are consistent with these ideas. Furthermore, also according to the literature review, we found that the variable which describes place of residence in urban areas (urbparish) is positively related with the dependent variable. As expected, this result indicates that the propensity of the residents to have a frequent or a very frequent contact with tourist is higher among the residents 
that live in urban parishes.

Table 3

Results of the Logit Regression Model

\begin{tabular}{lllllll}
\hline Contact & Coef. & Std. err. & \multicolumn{1}{l}{$z$} & $P>|z|$ & Marginal effects & Std. err. \\
\hline fac1 & 0.2480343 & 0.1314213 & 1.89 & 0.059 & 0.0560087 & 0.02957 \\
fac2 & -0.1912108 & 0.1240768 & 1.54 & 0.123 & -0.0431774 & 0.02798 \\
fac3 & 0.0766551 & 0.1185427 & 0.65 & 0.518 & 0.0173095 & 0.02676 \\
age & -0.1637721 & 0.2518184 & -0.65 & 0.515 & -0.0369639 & 0.05678 \\
gender & -0.0012962 & 0.0070124 & -0.18 & 0.853 & -0.0002927 & 0.00158 \\
education & 0.7832878 & 0.2698776 & 2.90 & 0.004 & 0.1742102 & 0.0583 \\
income & 0.17769 & 0.259589 & 0.68 & 0.494 & 0.0401222 & 0.05856 \\
linksector & -0.0483337 & 0.3226375 & -0.15 & 0.881 & -0.0108606 & 0.07213 \\
urbparish & 0.7247167 & 0.3365919 & 2.15 & 0.031 & 0.1507566 & 0.06294 \\
constant & -1.570376 & 0.4884404 & -3.22 & 0.001 & & \\
\hline
\end{tabular}

Note. Source: Authors' own survey data.

On the other hand, the variables representing the perceived negative impacts, age and gender of residents and their work links with the tourism industry present negative coefficient signs but are not statistically significant ( $p$-value $>0.1$ ). Just looking to the coefficient sign, if the result of the two first variables was the one expected, as younger people tend to be more receptive to tourism and to contact with visitors, and the perception of negative impacts negatively affects the level of interaction that residents tend to keep with visitors, the result attained for the linksector variable, which refers to the residents who have a job directly connected to the tourism industry, was particularly unexpected.

According to Table 3, besides the confirmed tendency of younger residents, mainly those endowed with higher levels of education and positive perceptions towards tourism, to maintain frequent contact/interaction with tourists, the same propensity for a frequent or very frequent contact with tourists is also ordinary found among residents who live in predominantly urban areas.

Socio-demographic variable describing gender and perceptions that tourism causes negative economic, social-cultural and environmental impacts are negatively related to the dependent variable. This points to the idea that the propensity of the residents to have a frequent or very frequent contact with tourists is inferior among female residents and among those that have a stronger perception of the possible negative impacts of the industry), but are not statistically significant ( $p$-value $>0.1$ ) in any of these cases.

As underlined above, the more surprising result was that residents with non-tourism related jobs have more propensity to contact with tourists than those with tourism related jobs. Probably those working in the sector are limited to contact with tourists on a professional level.

Regarding the first hypothesis (that the probability of residents having a frequent or very frequent contact with visitors is influenced by their perception of positive impacts/benefits of tourism), Table 3 suggests that the null hypothesis should be rejected, which means that the perceived positive impacts significantly affect the frequency of contact with tourists ( $p$-value $=0.059<0.1$ ).

The second research hypothesis examines whether the perceived negative impacts of tourism influence the probability of having a frequent or very frequent contact with visitors. According to the associated $p$-value 
shown in Table 3, the null hypothesis of this test should not be rejected ( $p$-value $=0.123>0.1$ ). The conclusion from this result is that the perceived negative impacts are not a significant predictor of having a frequent or very frequent contact with tourists.

The last research hypothesis is that socio-demographic characteristics, such as gender, age, education, income and place of residence, influence the probability of having a frequent or very frequent contact with visitors. Table 3 indicates that, from the socio-demographic variables considered in the analysis, only education and urbparish are significant predictors. In addition, the table shows that these regressors have a positive estimated coefficient. These results suggest that higher education level and living in urban areas are factors that positively influence the propensity to have a frequent or very frequent contact with visitors.

Bearing in mind the set of variables used and the results obtained, we believe that in future research the range of variables should be extended in order to obtain more consistent factors and more conclusive data from the study of this phenomenon. Further research should, of course, also try to work with a more representative survey sample.

\section{Concluding Remarks}

In recent years, peripheral regions have been profiting of the expansion of the tourism industry. In fact, a significant amount of tourists are now seeking other types of tourism destination than the mass ones, in this way trying to reach unspoilt landscapes and authentic experiences (Nepal, 2008). In what regards Guimarães, we know that the city experienced a continuous increase of visitors in the last 10 years, mostly after the nomination by UNESCO of its historical centre as world heritage. The same way, the hosting of the 2012 European Capital of Culture will certainly contribute to give the destination a more suitable position as a cultural tourism destination, through the general visibility that such an event gives to the hosting cities. In this context, its geographical centrality within the northern part of Portugal and the circumstance of being quite close to the border with Galicia act as facilitating factors.

The sample we made use in our investigation follows the socio-demographic characteristics of other ones undertaken in similar empirical researches (see for example, Sharma \& Dyer, 2009), even if one must take into account a few differences in the social and economics status of the survey respondents.

Using a factorial analysis and taking into account 13 items loaded on three factors (labeled as "positive impacts", "negative impacts", and "governance”), we can conclude that these three factors explain $52.3 \%$ of the variance contained in the original variables obtained from the survey. By another side, using a logit model in the analysis and taking as the dependent variable the frequent or very frequent contact with tourists, we found that only the variables referred to perceived positive impacts of tourism, education and the place of residence in urban areas have shown to be statistically significant.

These results follow investigations hold before, as individuals with higher levels of education tend to be more receptive to contact with persons endowed with a different culture and tend to be better informed about cultural tourism. The language skills acquired by more educated people can additionally be an important explaining factor of that result. We also found a tendency of residents that live in urban parishes (eight of them are the only ones that have tourism potential) to have a more frequent or very frequent contact with tourists.

In future investigations we envisage to go deep in the evaluation of the influence of birthplace, length of 
residence and community attachment in the perception kept by residents of the impacts of the tourism industry. We collected some evidence that those can be relevant factors under the attitude of residents toward tourists and cultural tourism. As far as we know, just a few empirical studies have centered their approach on these variables. More commonly, researchers have centered their attention on traditional demographic variables, as gender, age, education or income.

As said, the hosting of the 2012 European Capital of Culture will be a good opportunity for Guimarães to get a positioning as a relevant cultural tourism destination. Anyway, more than in common circumstances, in order to reach that goal there is the need to induce the residents accepting to be part of the envisaged tourism project, as they are an essential part of the cultural tourism experience that a city can offer to its visitors. So, if that should be the case, there is no other option to be followed by the local authorities and tourism agents than to take into account residents' opinions about the issue in all planning and management process.

A clear indication that the Guimarães residents claim to be listen and to participate in the tourism options to be taken and in the programming of the cultural events could be found not long ago (February 1, 2011) in an article published in a national newspaper (Jornal de Notícias). The title of the article (Guimarães 2012, capital of silence) said almost everything about the issue. Going deep in the article, one could find the claiming of several heads of local cultural associations of getting answers from the Guimarães City Foundation (the structure in charge of the planning of the event) about the proposals they had submitted. In some cases, one and a half year had passed without getting any answer to their proposals.

We are aware of the multiple ways the issue of residents' perceptions and attitudes towards tourism can be approached and of the difficulties to get useful policy oriented insights. This paper is a step in that trail. Further steps should be given, learning from the experience acquired.

\section{References}

Ap, J. (1992). Residents’ perceptions on tourism impacts. Annals of Tourism Research, 19(4), 665-690.

Ap, J., \& Crompton, J. (1993). Residents' strategies for responding to tourism impacts. Journal of Travel Research, 32(1), 47-50.

Besculides, A., Lee, M., \& McCormick, P. (2002). Residents' perceptions of the cultural benefits of tourism. Annals of Tourism Research, 29(2), 303-319.

Brunt, P., \& Courtney, P. (1999). Host perceptions of sociocultural impacts. Annals of Tourism Research, 26(3), 493-515.

Cadima Ribeiro, J., \& Remoaldo, P. (2011). Cultural heritage and tourism development policies-The case of a Portuguese U.N.E.S.C.O. World Heritage City (Chapter 4 of Part 4, Tourism planning and development), Economics and Management of Tourism: Tendencies and Recent Developments (pp. 199-223), Coelho, M.; Matias, Á. (orgs.), Universidade Lusíada Editora, Colecção Manuais, Lisbon.

Cordero, J. (2008). Residents' perception of tourism: A critical theoretical and methodological review. Ciencia Ergo Sum, 15(1), 35-44.

Crouch, G., \& Ritchie, J. (1999). Tourism, competitiveness, and societal prosperity. Journal of Business Research, 44(3), 137-152.

Eusébio, C., \& Carneiro, M. (2010). A importância da percepção dos residentes dos impactes do turismo e da interacção residente-visitante no desenvolvimento dos destinos turísticos. Pen drive, International Meeting on Regional Science: The Future of Cohesion Policy, APDR and AECR, Elvas and Badajoz, November 17-19, p. 25.

Getz, D. (1994). Residents' attitudes towards tourism: A longitudinal study in Spey Valley, Scotland. Tourism Management, 15(4), 247-258.

Hair, J., Anderson, R., Tatham, R., \& Black, W. (1998). Multivariate data analysis with readings. Englewood Cliffs: Prentice Hall. Hernandez, S., Cohen, J., \& Garcia, H. (1996). Residents attitudes towards an instant resort enclave. Annals of Tourism Research, 23(4), 754-779.

Instituto Nacional de Estatística. (2009). Estimativas provisórias da população residente 2008. Tema C—População e Sociedade. Lisbon. Retrieved December 14, 2010, from http://www.ine.pt 
Jackson, L. (2008). Residents' perceptions of the impacts of special event tourism. Journal of Place Management and Development, 1(3), 240-255.

Kuvan, Y., \& Akan, P. (2005). Residents' attitudes toward general and forest-related impacts of tourism: The case of Belek, Antalya. Tourism Management, 26, 691-706.

Lankford, S. (1994). Attitudes and perceptions toward tourism and rural regional development. Journal of Travel Research, 32(3), 35-43.

Lankford, S., \& Howard, D. (1994). Developing a tourism impact attitude scale. Annals of Tourism Research, 21(1), 121-139.

Lankford, S., Williams, A., \& Knowles-Lankford, J. (1997). Perceptions of outdoor recreation opportunities and support for tourism development. Journal of Travel Research, 35(3), 65-69.

Lawson, R., Williams, J., Young, T., \& Cossens, J. (1998). A comparison of residents' attitudes towards tourism in 10 New Zealand destinations. Tourism Management, 9(3), 247-256.

Loureiro, M., \& Jervel-Moxnes, A. (2004). Analysing farms' participation decision in agro-tourism activities in Norway: Some welfare implications. American Agriculture Economics Association Annual Meeting, Denver, August 1-4.

Machado, D. (2011). Guimarães 2012, Capital do silêncio. Retrieved February 10, 2011, from http://www.jn.pt/PaginaInicial/Cultura/Interior.aspx?content_id=1772017\&page=-1

Mason, P., \& Cheyne, J. (2000). Residents' attitudes to proposed tourism development. Annals of Tourism Research, 27(2), 391-411.

McDwall, S., \& Choi, Y. (2010). A comparative analysis of Thailand residents’ perception of tourism impacts. Journal of Quality Assurance in Hospitality and Tourism, 11(1), 36-55.

Monjardino, I. (2009). Indicadores de Sustentabilidade do Turismo nos Açores: o papel das opiniões e da atitude dos residentes face ao Turismo na Região. $15^{\circ}$ Congresso da APDR—Redes e Desenvolvimento Regional, Cabo Verde, Praia, July 9-11.

Murphy, P. (1985). Tourism: A community approach. New York: Methuen.

Nepal, S. K. (2008). Residents' attitudes to tourism in Central British Columbia, Canada. Tourism Geographies, 10(1), 42-65.

Nunnally, J. (1978). Psychometeric theory. New York: McGraw-Hall.

Pearce, P., Moscardo, G., \& Ross, G. (1996). Tourism community relationships. Oxford: Pergamon Press.

Ritchie, B., \& Inkari, M. (2006). Host community attitudes toward tourism and cultural tourism development: The case of the Lewes District, Southern England. International Journal of Tourism Research, 8, 27-44.

Ryan, C., \& Montgomery, D. (1994). The attitudes of Bakewell residents to tourism and issues in community responsive tourism. Tourism Management, 15(5), 358-369.

Sharma, B., \& Dyer, P. (2009). An investigation of differences in residents’ perceptions on the Sunshine Coast: tourism impacts and demographic variables. Tourism Geographies, 11(2), 187-213.

Souza, C. (2009). Turismo e desenvolvimento: percepções e atitudes dos residentes da Serra da Estrela (Master dissertation in Management and Planning in Tourism, University of Aveiro).

Vareiro, L., Cadima Ribeiro, J., Remoaldo, P., \& Marques, V. (2011). Residents’ perception of the benefits of cultural tourism: The case of Guimarães. In A. Steinecke, \& A. Kagermeier (Eds.), Kultur als Touristischer Standortfaktor-Potenziale-Nutzung-Management (pp. 187-202). University of Paderborn, Germany, Paderborner Geographische Studien zu Tourismusentwicklung und Destinationsmanagement (Paderborn Geographical Studies), Institute series No. 23.

Williams, J., \& Lawson, R. (2001). Community issues and resident opinions of tourism. Annals of Tourism Research, 18(2), 269-290.

Wooldridge, J. (2006). Introductory econometrics: A modern approach. Mason: Thompson (South-Western).

Zhang, J., Inbakaran, R., \& Jackson, M. (2006). Understanding community attitudes towards tourism and host-guest interaction in the urban-rural border region. Tourism Geographies, 8(2), 182-204. 